\title{
Onsite training of clinicians on new techniques to improve cervical cancer prevention in sub-Saharan Africa
}

\author{
Joel Fokom Domgue, Houston, USA, Yaounde, Cameroon; Florence Manjuh, Yaounde, Cameroon; Kathleen Nulah, \\ Bamenda, Cameroon; Thomas Welty, Bamenda, Cameroon and Alan Waxman, Albuquerque, USA
}

Cervical cancer remains a leading cause of death in African women. ${ }^{1}$ While screening and treatment of cervical pre-cancerous lesions are highly effective preventive strategies, most women in Africa have never been screened due to the lack of resources, including a well-trained workforce to implement these strategies.

Since 2007 the Women's Health Program, a nurse-led program of the Cameroon Baptist Convention Health Services, a faith-based healthcare organization in Cameroon, has screened more than 100000 women for cervical cancer in seven of the 10 regions of Cameroon. ${ }^{2}$ The Women's Health Program employs visual inspection with acetic acid and Lugol's iodine enhanced by digital cervicography using digital cell phone cameras to project enlarged cervical images to monitors for viewing by patients and providers. ${ }^{3}$ With the advent of emerging technologies, it is critical to update clinicians' skills in order to offer high quality care to patients. Women's Health Program clinicians and providers from other organizations expressed the need for comprehensive training in detection and management of cervical pre-invasive and early invasive disease. This led to the establishment of a telementoring program, where experts provide guidance to local staff to adequately manage their patients. ${ }^{4}$ To complement this ongoing distant learning process, clinicians requested onsite hands-on training on new techniques of diagnosis and management of cervical cancer precursors. In response, the American Society for

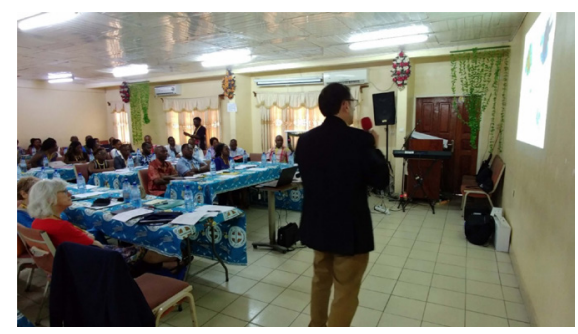

Figure 1 Dr Greenspan lecturing during the classroom teaching.
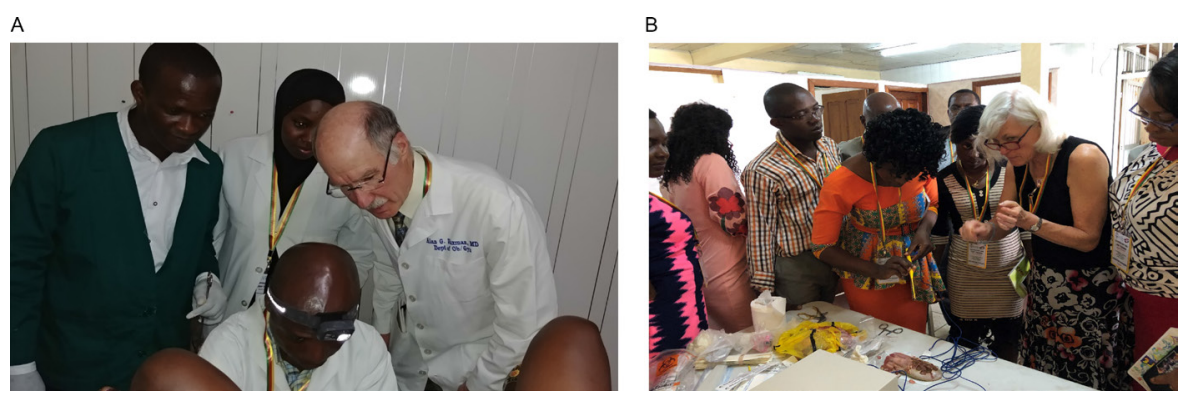

Figure 2 (A) Dr Waxman with students at the hands-on colposcopy training. (B) Dr Fry with students at the hands-on loop electrical excision procedure simulation using beef tongue.
Colposcopy and Cervical Pathology (ASCCP) partnered with the Cameroon Baptist Convention Health Services and the National Cancer Control Committee of Cameroon to hold a comprehensive course on human papillomavirus (HPV), cervical cancer prevention, colposcopy, and loop electrical excision procedure in Douala, Cameroon in April 2019. Four ASCCP instructors lectured on HPV epidemiology and testing, cervical cancer screening and clinical management of preinvasive disease, and colposcopy combined with hands-on clinical experience (on actual patients) with biopsy and colposcopy, loop electrical excision procedure, and thermal coagulation using battery powered devices.

Doctors and nurses from three countries (Cameroon 38, Nigeria 3, Sudan 1) participated in the 3 days of didactic lectures, interactive case presentations and simulations in colposcopy, loop electrical excision procedure, and thermal coagulation (Figure 1). This was followed by 4 days of hands-on colposcopy and loop electrical excision procedure training in a clinical setting for 15 doctors/ nurses (Figure 2A,B). From January through March 2019, the 10 Women's Health Program clinics screened 3136 women and identified 61 women with presumptive diagnoses of loop electrical excision procedure-eligible lesions (per World Health Organization criteria), based on visual inspection with acetic acid and Lugol's iodine enhanced by digital cervicography using digital cell phone cameras. These women were offered free evaluation and treatment under close supervision by the ASCCP faculty as part of the training. To facilitate the learning process, images from hand-held digital colposcopes were displayed on video monitors. Of the 55 women who came to the loop electrical excision procedure practicum, 44 received loop

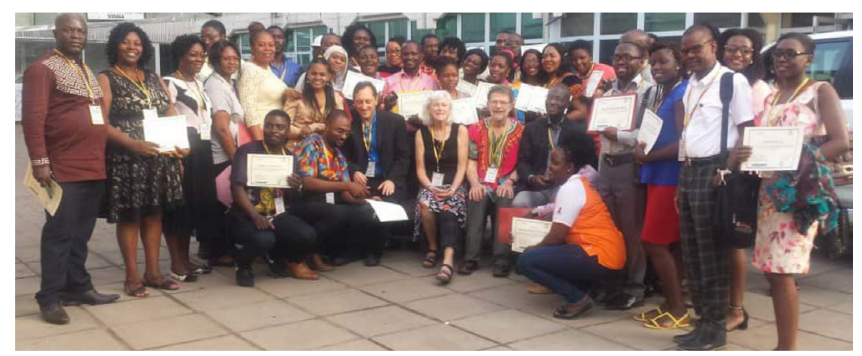

Figure 3 Faculty and participants of the cervical cancer prevention and colposcopy course with their certificates, Mboppi Baptist Hospital, Douala, Cameroon. 


\section{Corners of the world}

electrical excision procedure, nine had biopsies, and two were scheduled for a hysterectomy or radiotherapy. The Cameroon Baptist Convention Health Services pathologist read all tissue specimens to guide follow-up and further treatment. The ASCCP faculty agreed with the clinical impressions of the Women's Health Program nurses in over $80 \%$ of the patients.

Trainees' knowledge at baseline and after the didactic program were assessed with a pre- and post-test. At the end of the course, all trainees received certificates of completion and had positive comments about the training (Figure 3). As a result of this high-quality onsite training, many women in Cameroon, Nigeria, and Sudan will benefit from improved cervical cancer preventive services.

Correspondence to Dr Joel Fokom Domgue, Gynecologic Oncology and Reproductive Medicine, University of Texas MD Anderson Cancer Center, Houston, TX 77030, USA; jfokom@mdanderson.org
Collaborators Edith Welty, David Greenspan, Laura Fry, Olesegun K. Ajenifuja, Richard Bardin, Simon Manga, Francine Kouya, Anthony Monjuh, Dean Wallace, Rose Ndinda, Kathleen Schmeler, Pius Tih.

Contributors AW, JFD, FM, KN, and TW planned and organized the training. AW and TW developed the training curriculum. AW selected the course instructors. JFD, TW, AW, and FM invited the course participants. JFD, AW, and TW drafted this manuscript, whose final version was approved by all authors.

Funding The onsite training in Cameroon was supported through donations to the ASCCP and the Cameroon Health and Education Fund.

Competing interests None declared.

Patient consent for publication Not required.

Provenance and peer review Commissioned; internally peer reviewed.

(c) IGCS and ESG0 2020. No commercial re-use. See rights and permissions. Published by BMJ.

\section{Check for updates}

To cite Fokom Domgue J, Manjuh F, Nulah K, et al. Int J Gynecol Cancer 2020;30:551-552.
Accepted 18 July 2019

Published Online First 30 August 2019

Int J Gynecol Cancer 2020;30:551-552. doi:10.1136/ijgc-2019-000772

\section{REFERENCES}

1. Manga S, Kanjo M, Ngwa W. Challenges with cervical cancer treatment in Cameroon. Obstet Gynaecol Cases Rev 2017;4.

2. DeGregorio G, Manga S, Kiyang E, et al. Implementing a fee-for-service cervical cancer screening and treatment program in Cameroon: challenges and opportunities. Oncologist 2017;22:850-9.

3. Manga S, Parham G, Benjamin N, et al. Cervical cancer screening in Cameroon: interobserver agreement on the interpretation of digital cervicography results. J Low Genit Tract Dis 2015;19:288-94.

4 Fokom Domgue J, Baker E, Manjuh F, et al. Connecting frontline providers in Africa with distant experts to improve patients' outcomes through Project Echo: a successful experience in Cameroon. Int $J$ Gynecol Cancer 2019;29:1446-7. 